\title{
Intervenciones poblacionales efectivas para promover la reducción de sodio
}

\author{
Effective population based interventions to promote sodium reduction
}

Mohan S y col. CMAJ. 2009 Oct 27; 181(9):605-9.

\section{Objetivo}

Revisar la evidencia científica sobre intervenciones poblacionales para promover la reducción de sodio en la dieta y su repercusión sobre la salud, en el contexto de la Carta de Ottawa para la Promoción de la Salud.

\section{Fuente y selección de Datos}

Utilizando como descriptores los términos "estrategias poblacionales", "políticas en sodio", "acción comunitaria para la reducción de la sal", "elecciones alimentarias saludables", y "rol del sistema de salud", los autores buscaron en MEDLINE (1980 a 2008) trabajos con revisión de pares sobre intervenciones para reducir el consumo de sodio en la dieta; así como reportes y literatura gris en Google Académico y sitios gubernamentales. Resumieron narrativamente los mejores resultados agrupándolos en diferentes tópicos: impacto del exceso de consumo, políticas y estrategias, colaboración y regulación de la industria alimentaria, etiquetado, reformulación de productos, educación pública, sustitución de sal e intervenciones a niveles no gubernamentales.

\section{Resultados Principales}

La Organización Mundial de la Salud (OMS) recomienda una ingesta diaria de sodio no mayor a dos gramos. Para lograr esta meta las políticas públicas pueden enfocarse en reformular el contenido de alimentos procesados, en educar a los consumidores, y en aumentar la disponibilidad de productos bajos en sodio. El mejor ejemplo es Finlandia, que ha implementado políticas basadas en la población ancladas en la colaboración y regulación de la industria alimentaria, y en la educación a través de medios masivos de comunicación. Estas políticas se vieron reforzadas por la acción voluntaria de la industria y resultaron en un $40 \%$ de dis- minución del consumo de sodio, en una reducción de hasta 10 $\mathrm{mmHg}$ en la media poblacional de presión arterial diastólica, y hasta en un $70 \%$ de reducción en la mortalidad por enfermedad cardiovascular (ECV) y cerebrovascular isquémica, a lo largo de más de tres décadas. Los demás países desarrollados cuyas intervenciones poblacionales fueron analizadas en la revisión, comenzaron sus programas a partir de 2000. En EEUU no se logró reducir el consumo de sodio. Si bien el etiquetamiento de alimentos ha probado ser útil en el Reino Unido, la reducción del consumo de sodio fue pequeña. En Canadá comenzaron intervenciones voluntarias de la industria combinadas con educación pública, siendo aun temprano para evaluar los resultados.

\section{Conclusiones}

Globalmente entre un 17 y un $30 \%$ de la hipertensión arterial podría ser explicada por exceso de sodio dietario, por lo que constituye un problema mayor de salud pública. Si bien se han observado importantes reducciones en la incidencia de ECV en distintos estudios controlados de intervención dietaria, es trascendente la acción efectiva tanto del gobierno como de las Organizaciones No Gubernamentales (ONG) interesadas en mejorar la salud pública. Si no existe en un país la acción voluntaria por parte de la industria, entonces los gobiernos deberían utilizar medidas regulatorias. El etiquetado de alimentos, las campañas en medios masivos, el monitoreo de procesos y la educación de los consumidores son las estrategias a seguir.

Palabras claves: estilos de vida, hipertensión arterial, enfermedad cardiovascular, estrategias poblacionales, consumo de sodio, prevención.

Keywords: life style, hypertension, cardiovascular disease, population strategies, sodium consumption, prevention.

Fuentes de financiamiento: no referida. Apoyo económico: uno de los autores recibió apoyo de compañías farmacológicas que producen anti-hipertensivos.

\section{Comentario}

La relevancia de la alimentación saludable y la actividad física para la salud pública fue remarcada por la OMS en su "Estrategia Mundial de Alimentación Saludable y Vida Activa", aprobada desde 2004 por los países miembros. La reducción de sodio constituye un punto clave para las acciones de los gobiernos que respaldan dicha estrategia.

Para la mayoría de los países de América Central y América Latina y el Caribe, varios factores contribuyen a que el consumo de sal en la dieta sea elevado. Acciones como el etiquetado nutricional, el análisis de los nutrientes y el control regulatorio son poco frecuentes en nuestra región. En Argentina, la Encuesta Nacional de Factores de Riesgo y la de Nutrición y Salud ${ }^{1}$ del Ministerio de Salud ${ }^{2}$ mostraron que un tercio de la población argentina adulta padece hipertensión arterial. Por otro lado, los productos de panadería explican aproximadamente el $25 \%$ del consumo de sal por persona en Argentina, y los alimentos procesados, un porcentaje similar; lo que conduce a pensar que cambios en la elaboración de estos produc- tos presentan la potencialidad de reducir significativamente el consumo masivo de sodio.

\section{Conclusiones del comentador}

Si bien la información epidemiológica proveniente de estudios transversales es sin duda necesaria, nuestros países pueden -sin esperar a actualizarla- elegir y adaptar una serie de tácticas y modelos de éxito probados en otros lugares para sensibilizar a los medios de comunicación y a los consumidores, y para movilizar a la comunidad científica, comunidad y profesionales de la salud. En este sentido, vale destacar que en Argentina se están realizando esfuerzos desde 2009 para facilitar el establecimiento de un Grupo de Trabajo sobre la reducción de sal dietaria desde el Ministerio de Salud, la Organización Panamericana de la Salud y la Agencia Canadiense de Salud Pública.

Ver glosario*

Ariel Bardach [ Centro de Excelencia en Salud Cardiovascular para el Cono Sur de América. Instituto de Efectividad Clínica y Sanitaria, Buenos Aires. abardach@gmail.com ]

Bardach A. Intervenciones poblacionales efectivas para promover la reducción de sodio. Evid. actual. práct. ambul; 12 (4): 125, Oct-Dic.2009. Comentado de: Mohan S, Campbell NR, Willis K. Effective population-wide public health interventions to promote sodium reduction. CMAJ. 2009 Oct 27; 181(9):605-9. Epub 2009 Sep 14. PMID: 19752102. Disponible libremente en URL: http://www.cmaj.ca/cgi/content/full/181/9/605 (último acceso 01/12/09).

\section{Referencias}

1. Ministerio de Salud de la Nación Encuesta Nacional sobre Nutrición y Salud Disponible en URL http://www.msal.gov.ar/htm/Site/ennys/site/default.asp (último acceso: 01/12/09). 2. Ministerio de Salud de la Nación Encuesta Nacional Sobre Factores de Riesgo. 2006. Disponible en URL: http://www.msal.gov.ar/htm/Site/enfr/resultados.asp (último acceso: 01/12/09). 